\title{
Punto de vista e investigación: el caso del zapatismo
}

\author{
Jérôme Baschet
}

\section{Marco Estrada Saavedra y}

Juan Pedro Viqueira (coords.), 2010

Los indigenas de Chiapas y la rebelión zapatista. Microhistorias politicas

El Colegio de México, Distrito Federal, 460 pp.
$\mathrm{E}_{\text {por Marco Estrada Saavedra y }}^{\text {sta reseña del libro coordinado }}$ Juan Pedro Viqueira pretende discutir algunos aspectos y planteamientos generales de las investigaciones académicas que se han dedicado, en los últimos años, al zapatismo. Comentar principalmente trabajos realizados desde posturas adversas al zapatismo me llevará a plantear algunas observaciones sobre la cuestión del punto de vista en la investigación social.
Deseoso de "releer el zapatismo desde abajo" (Juan Pedro Viqueira), el presente libro reúne siete microhistorias de comunidades o ejidos (y, en un caso, de un municipio), ubicados en las distintas regiones del Chiapas indígena (Los Altos, el Norte, la Selva, Las Cañadas de Ocosingo, la región tojolabal). Los estudios asumen una forma esencialmente narrativa, nutrida por abundante información de carácter

\section{Perspective and Research: the Case of Zapatismo}

JÉrôme Baschet: Universidad Autónoma de Chiapas; Escuela de Altos Estudios en Ciencias Sociales, París

Jerome.Baschet@ehess.fr

Desacatos, núm. 33, mayo-agosto 2010, pp. 189-201

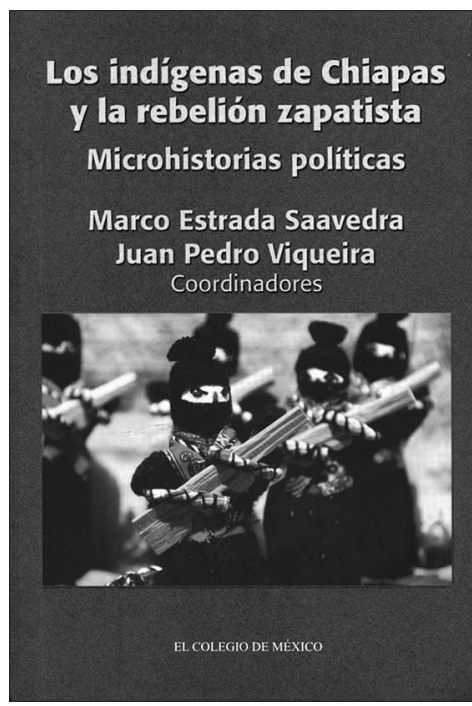

histórico y etnográfico. En particular, varios de los autores reconstituyen con sólidos apoyos documentales la historia agraria de las comunidades o ejidos estudiados. Cada uno de estos relatos resulta un viaje al "infierno agrario mexicano" ${ }^{\text {. }}$. Particularmente im-

\footnotetext{
${ }^{1}$ Para retomar una expresión de Federico Anaya en la presentación del libro en San Cristóbal de Las Casas, el 12 de enero de 2010.
} 
pactante es el caso de La Garrucha, estudiado por Hadlyyn Cuadriello Olivos y Rodrigo Megchún Rivera. Al recibir su primera dotación, sus habitantes vieron que les habían otorgado tierras pedregosas ubicadas en las partes altas del cerro, $y$ tuvieron que lidiar durante 35 años para conseguir la ejecución de una resolución presidencial que les entregaba tierras de mejor calidad. Impresionante también es, en la narración de Marina Alonso Bolaños, el caso de los damnificados zoques, que después de la erupción del Chichonal, en 1982, fueron reubicados en la Selva, donde formaron el poblado Nuevo Francisco León. La dotación ejidal les fue entregada en 1991, pero no tardaron en darse cuenta de que las 3300

hectáreas medidas por la Secretaría de la Reforma Agraria se encontraban, casi en su totalidad, en el territorio concedido desde 1972 a la comunidad lacandona, lo cual provocó una situación conflictiva que no ha podido resolverse hasta la fecha. En fin, el caso más común es el de tantos ejidos que durante décadas han multiplicado trámites en los laberintos de la burocracia y han realizado movilizaciones sin poder conseguir la ampliación solicitada, lo que constituye uno de los factores decisivos de radicalización política de las comunidades y es una de las condiciones que generaron gran receptividad hacia la vía alterna planteada por el Ejército Zapatista de Liberación Nacional (EZLN).

En segundo lugar, el libro evidencia los beneficios que el levanta- miento zapatista trajo para los no zapatistas. Muchos de ellos aprovecharon la coyuntura de enero de 1994 para tomar las tierras que anhelaban desde tiempo atrás sin haber podido conseguirlas por la vía legal, como es el caso de los ejidos Veracruz, Saltillo y, al parecer, del barrio El Coloquil ${ }^{2}$. Conscientes de que el levantamiento había significado "un gran susto" para el Estado, muchas organizaciones campesinas de Chiapas utilizaron esta correlación de fuerzas para satisfacer reclamos que las autoridades no habían atendido durante décadas. Además, los beneficios no fueron solamente materiales: diversos testimonios revelan cómo la ocupación de varias cabeceras municipales de Los Altos resultó un motivo de orgullo para muchos indígenas, incluso no zapatistas, y una inspiración para resistir las arbitrariedades y el racismo de los ladinos. Es oportuno reconocer las muchas transformaciones que el zapatismo ha contribuido a generar, tanto en las dinámicas internas de las comunidades (especialmente en las relaciones de género) como en la representación y la autorrepresentación de los indígenas.

\footnotetext{
${ }^{2}$ Por la violencia que se ha desatado en la zona Norte, el estudio de comunidades como El Limar y El Coloquil es muy delicado. La reconstitución propuesta por Alejandro Agudo Sanchiz (pp. 217-275) contiene aportaciones sugerentes en lo que se refiere a la historia de las difíciles relaciones entre las dos comunidades. Sin embargo, en su época más reciente no puede considerarse como comprobada, en particular cuando parece descartar la presencia de bases zapatistas tanto en El Coloquil como en El Limar.
}

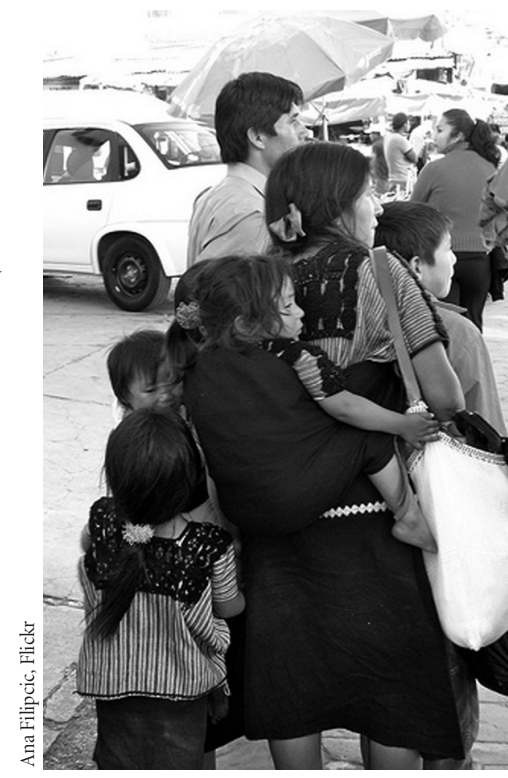

Niños, 2010.

Destaca el estudio que Eufemio Aguilar Hernández, Martín Díaz Teratol y Juan Pedro Viqueira dedican a la historia del municipio de San Andrés Larráinzar (o Sakamch'en de los Pobres, por su parte autónoma), entre 1959 y 2005. Los autores buscan analizar los factores que han llevado a la población, a pesar de episodios muy tensos, a una convivencia pacífica entre zapatistas y no zapatistas, así como entre las dos autoridades municipales, la oficial y la autónoma. Además de varios otros aspectos, subrayan el papel de algunos actores clave y, de paso, comprueban la implicación del gobierno estatal en la política contrainsurgente de paramilitarización. A pesar de haber sido presionado por funcionarios estatales, en 1994-1995, para formar grupos armados antizapatistas, el presidente 


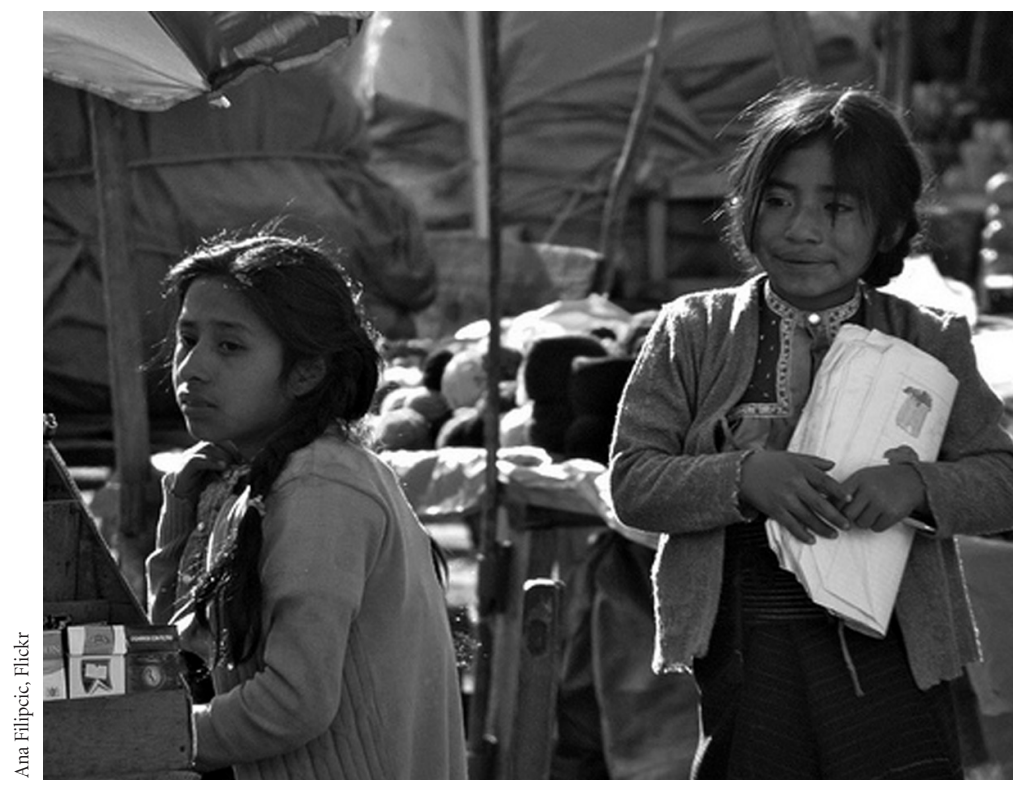

Indigenas, 2010.

municipal de San Andrés logró evadir dichas incitaciones, amenizadas con una garantía de impunidad y la promesa de una diputación (pp. 393394). Por lo tanto, una de las razones por las cuales se ha podido mantener una relación de respeto entre zapatistas y no zapatistas es que los sanandreseros descartaron las intromisiones gubernamentales que, en otros municipios, han propiciado una violencia desenfrenada. De manera más general, se puede apreciar la capacidad de los tsotsiles de San Andrés para organizar su vida colectiva mediante acuerdos, y así mantener relaciones aun de cooperación entre quienes han optado por apartarse de las instituciones del Estado y quienes siguen integrados en ellas. El estudio da toda su dimensión a este éxito y reconoce los logros del municipio autónomo, en particular en la resolución de conflictos, a tal punto que "muchas personas, incluso si no simpatizan con los zapatistas, acuden al ayuntamiento autónomo porque le reconocen una mayor seriedad y un mayor sentido de equidad" (p. 384).

Éstas son algunas de las aportaciones del libro que los lectores de sensibilidades afines al zapatismo no deberían desaprovechar. $\mathrm{Al}$ respecto, es oportuno señalar la relativa pluralidad de inspiración manifestada en el volumen, aunque resulta evidente que muchos investigadores más cercanos al zapatismo no aportaron su contribución.

Los siete estudios de casos presentados no pueden ofrecer un panorama general o siquiera representativo de las comunidades zapatistas (o parcial- mente zapatistas) de Chiapas. Las consideraciones que abren el libro lo advierten con toda claridad. No por eso deja de ser cuestionable la selección de casos y situaciones que conforman este libro. De las siete contribuciones, dos se refieren a lugares emblemáticos del zapatismo (La Garrucha, sede de uno de los cinco Aguascalientes-Caracoles, y San Andrés Sakamch'en, sede de los Diálogos con el gobierno federal); dos más presentan a comunidades que se mantuvieron unos años en el EZLN (siete en el caso de Santa Catalina Huituipán, dos o tres en el de Buena Vista Pachtán); tres estudian comunidades que nunca fueron zapatistas (ejidos Veracruz y Saltillo), sólo declararon serlo en un determinado momento (El Coloquil) o bien se adhirieron a organizaciones simpatizantes del EZLN (Xi'Nich, en el caso de Nuevo Francisco León). Quizás se trate de dar cuenta del conjunto de relaciones que han podido existir entre las comunidades indígenas de Chiapas (incluyendo las que quedaron ajenas al zapatismo) y el movimiento zapatista. Sin embargo, la importancia que en el libro adquieren las comunidades no zapatistas y el hecho de que solamente en cuatro casos (o más bien tres) se estudian poblaciones con efectiva trayectoria zapatista pueden verse como un franco desequilibrio. Los casos presentados resultan insuficientes para entender lo que significa el zapatismo en las comunidades indígenas y para dar una visión, si no representativa, por lo menos significativa de la pluralidad de "los zapatismos" a la que aluden los coordinadores del volumen. Quizás no sea 
su propósito, pero de ninguna manera este libro podría pretender convertirse en un estudio de referencia sobre las comunidades zapatistas de Chiapas.

Por eso resulta muy cuestionable la postura asumida por Marco Estrada en sus consideraciones finales. Incluso parecen contradictorias con el espíritu del libro, tal como lo presenta Juan Pedro Viqueira, cuando aclara que cada autor tenía el encargo de narrar una historia, sin amplias consideraciones teóricas ni conclusiones generales, pero sin pretender esconder opciones metodológicas o inclinaciones políticas. Sorprende, por lo tanto, la manera en que Marco Estrada se otorga la libertad de asumir un discurso de naturaleza totalmente diferente, el cual más que entrelazar o prolongar los hilos de las distintas contribuciones, en buena medida se impone a ellas de manera forzada. Estrada se autoriza a dibujar un marco interpretativo que pretende dar cuenta de la trayectoria del zapatismo en Chiapas y elabora conclusiones de alcance general que, si bien se amparan en las acostumbradas precauciones retóricas de prudencia, carecen de legitimidad tanto por el número limitado de casos estudiados como por el modo parcial con el cual se refiere a (o elude) los datos proporcionados por los distintos autores $^{3}$. La forma en que estas consideraciones finales se sobreponen al conjunto de estudios que componen

\footnotetext{
${ }^{3} \mathrm{Si}$ bien es legítimo identificar puntos comunes, la forma en que procede Marco Estrada lo lleva a caer en generalizaciones abusivas, olvidándose de la proclamada diversidad regional. Por ejem-
}

el libro roza lo deontológicamente incorrecto. Y si acaso la expresión parece exagerada, optaría por calificarlas como un error un tanto perverso, en la medida en que se apoyan en la diversidad de las contribuciones para legitimar in fine un discurso muy personal, con el resultado de que el pluralismo relativo del libro termina sirviendo de sustento a un análisis marcado por una intencionalidad francamente antizapatista.

plo (p. 425), al querer resaltar las jerarquías internas de las comunidades y la búsqueda de prestigio, influencia y poder,

la formulación que reza "como lo ilustra el caso de El Limar y El Coloquil" permite utilizar un ejemplo (en el cual los fenómenos mencionados están efectivamente muy marcados) como argumento para validar una afirmación de carácter general, cuando nada comprueba que ésta se pueda aplicar de la misma manera en las distintas regiones consideradas, y en especial en Las Cañadas (por ejemplo, en el caso de La Garrucha). Asimismo, la insistencia sobre el papel de los "líderes comunitarios" en varios casos es pertinente, pero puede volverse una obsesión y un obstáculo etnográfico si termina negando completamente los mecanismos colectivos de consenso y en especial el propio papel de las asambleas comunitarias. Un ejemplo (entre tantos otros) de cómo la dinámica de estas asambleas no se ha apagado ni con el peso de los líderes comunitarios ni con la supuesta imposición de la estructura militar del EZLN se puede observar en el caso de Bayalemhó (San Andrés): ahí

(p. 400), los autores la identifican como un logro extraordinario y hasta como "un acto fundador de la modernidad", lo que efectivamente tiene algo de excepcional (en la medida en que se trata de una asamblea común convocada por los dos agentes municipales, el oficial y el autónomo), pero que no hace más que potenciar un recurso cultural histórico-tradicional que muchas comunidades se esfuerzan en revitalizar para decidir colectivamente sobre sus formas de vida. En este punto, el comentario de los autores busca desmontar una concepción esencialista de los "usos y costumbres" que, en realidad, no corresponde de ninguna manera a las concepciones zapatistas.
Veamos con más precisión estas "consideraciones finales". Como ejemplo de afirmación cuyo carácter sesgado se esconde detrás de un aparato "científico" imponente, pero manejado de manera tendenciosa, resalta la mención de que las comunidades zapatistas no representan, desde los primeros años del levantamiento, más que unos "archipiélagos [...] en medio de un océano de comunidades indígenas no zapatistas". Remite, para "ilustrar" esta metáfora, a un mapa basado en el trabajo de Willibald Sonnleitner (pp. 420-421). Sin embargo, si el lector evade el impacto visual del mapa - en un efecto que tiene más de ilusionismo que de rigor científico- y consulta los escritos del citado investigador, se dará cuenta de que indican lo siguiente: en 1995, de las 341 secciones electorales correspondientes a la llamada zona de conflicto, 224 se caracterizan por tener una presencia zapatista cercana a una tercera parte de los inscritos, mientras que en 105 rebasa la mayoría de ellos. ¿ Son islitas perdidas en un mar ajeno al zapatismo?, ¿se trata de un simple desliz semántico, que se suma curiosamente a muchos otros que se inclinan en la misma dirección?, ¿o habría que preguntarse cuál es la parte de manipulación en esta mención?

Muchas otras de las afirmaciones finales deforman o ignoran los datos presentados en el libro. Es sabido que las formas de explotación características de las fincas desde el siglo XIX ya habían sido desmembradas en lo esencial antes de 1994, pero no por eso se puede considerar a 
los conflictos agrarios que estallan a raíz del levantamiento como un "conflicto entre campesinos pobres" o afirmar que las tierras recuperadas "eran, en su gran mayoría, pequeñas propiedades privadas". El caso de La Garrucha difícilmente puede "ilustrar" estas conclusiones, ya que en sus alrededores permanecían en 1994 dos fincas de un millar de hectáreas y una decena de ranchos con una extensión promedio de 250 hectáreas. Es poco probable que los ejidatarios estén de acuerdo con el investigador en calificar estas propiedades de "pequeñas". De manera similar, resulta tendenciosa la forma en que Marco Estrada minimiza los alcances del reparto agrario "desde abajo", realizado en territorios zapatistas: evaluar las tierras repartidas entre una y tres hectáreas por familia no tiene mucho sentido, ni menos mencionar al respecto el caso de Buena Vista Pachtán, ya que casi la totalidad de las tierras recuperadas pasaron a manos de los miembros de la Central Independiente de Organizaciones Indígenas y Campesinas (CIOAC) (entre cuatro y cinco hectáreas por familia), mientras que en el caso de La Garrucha, obtener un complemento de 2.5 hectáreas de buenas tierras no puede considerarse insignificante. Por otra parte, esta valoración pasa por alto la creación, en las tierras recuperadas de Las Cañadas, de un número notable de "nuevos centros de población” (20 sólo en el municipio autónomo 17 de Noviembre), tal como lo han documentado varias investigaciones ${ }^{4}$.

De igual forma, la cuestión de las deserciones merecería un análisis más matizado y más atento que el que ofrece Marco Estrada en su afán por sustentar su diagnóstico global de "desmembramiento del zapatismo" (p. 432). La elección del término sorprende. Parece utilizado sin mucha atención al sentido exacto de la palabra (desmembrar: "1) dividir y apartar los miembros del cuerpo; 2) dividir, separar algo de otra cosa", según el Diccionario de la Real Academia Española), sino únicamente por la violencia (mal contenida) con la que permite golpear al zapatismo. Un uso tan poco cuidadoso del vocabulario sólo evidencia la prisa del autor por proclamar la muerte del movimiento zapatista. Sin embargo, dicho diagnóstico no corresponde ni a lo que se puede saber de la situación en Chiapas, ni a la información proporcionada en el libro. Los ejemplos de La Garrucha y San Andrés - los únicos casos con amplia trayectoria zapatista estudiados aquí- no dan ninguna indicación para acreditar un supuesto desmembramiento, sino más bien comprueban una resistencia singular. De cualquier forma, el autor se empeña en acumular datos e información (no siempre comprobados) con la intención de subrayar los límites y los fracasos del zapatis-

\footnotetext{
${ }^{4}$ Van der Haar, 2004 (se evalúan en 19000 hectáreas las tierras recuperadas del municipio 17 de Noviembre); Mora, 2008.
}

mo, haciendo caso omiso de los logros y avances señalados en los dos textos mencionados. Es particularmente alarmante que las aportaciones del estudio relativo a San Andrés -el único que analiza la manera en que los zapatistas han desarrollado sus gobiernos autónomos- estén casi totalmente ignoradas en las consideraciones finales. Junto con la opción en favor del estudio de otras comunidades (lo cual tiende a eclipsar a los municipios autónomos y las Juntas de Buen Gobierno), este procedimiento permite descartar cualquier evaluación seria de la construcción de la autonomía que, sin embargo, constituye el corazón de la experiencia zapatista. Permite evadir el hecho de que en San Andrés, como en las Juntas y en otros municipios más, los zapatistas han creado formas de gobierno que muchos indígenas, zapatistas y no zapatistas, llegan a considerar más justas y más cercanas a ellos que las opacas y a menudo adversas estructuras del Estado mexicano. De la misma manera, la valoración que Estrada dedica a la educación autónoma resulta sumamente parca ("insuficiencias en salud y educación”), lo que contribuye a restarle credibilidad a su evaluación global de la situación del zapatismo. En efecto, el campo educativo permite comprobar una extensa movilización colectiva de miles de actores (promotores, padres de familia y alumnos, comités, patronatos, autoridades municipales y Juntas, apoyos solidarios) que demuestra una amplia "apropiación social del espa- 
cio educativo", sin la cual sería impensable hacer funcionar, en las condiciones de la resistencia, unas 500 escuelas donde 16000 alumnos son atendidos por unos 1300 promotores $^{5}$. En particular, en Los Altos de Chiapas - y es un dato que actualiza el estudio sobre San Andrés- alrededor de 80 escuelas primarias autónomas abrieron sus puertas a partir de 2005. Si se añade que, en más de seis años de existencia - $\mathrm{y}$ sin esconder enormes dificultades y bajas reconocidas por el mismo EZLN-, las Juntas de Buen Gobierno han podido mejorar su organización, su capacidad de resolución de los problemas y de interacciones con los actores exteriores, entonces la dinámica y el crecimiento de la experiencia autonómica

1944 - 4 especial en el ejercicio del autogobierno, la justicia y la educación- de ninguna manera podría entenderse en el contexto de la agonía apresuradamente diagnosticada por el doctor Marco Estrada.

Si las consideraciones finales revelan un uso muy discutible de la generalización, también contienen afirmaciones que merecen discusión. Algunas se refieren a la relación entre la estructura político-militar del EZLN y sus bases de apoyo, la cual viene definida en términos de "integración, vigilancia y control", para poder "imponer la autoridad de la comandancia insurgente sobre las bases de apoyo para

\footnotetext{
${ }^{5}$ Baronnet, 2009
}

asegurar su predomino sobre ésta través [sic] de una estricta disciplina asegurada por medio de prohibiciones y sanciones, así como de incentivos y beneficios" (p. 428). Encontramos aquí el tema de la "comunidad armada rebelde", planteado por Estrada (2007) en un libro anterior y retomado en su estudio sobre Buena Vista Pachtán (p. 96). Cabe mencionar que, en ambos trabajos, dicha noción viene definida de manera bastante vaga y no sin ambigüedades. Quizás haya prevalecido la voluntad de forjar una expresión connotada negativamente al sugerir una profunda militarización, pero el resultado termina dificultando la comprehensión de los procesos característicos de las comunidades zapatistas. Intenta expresar lo que Estrada considera como una estricta sumisión de las comunidades a los mandos militares del EZLN y a su autoritarismo rígido. Al mismo tiempo, el análisis mantiene una franca dualidad entre las comunidades y el EZLN, descritos como "dos sistemas sociales" distintos (a tal punto que parece excluir la posibilidad de pensar que las bases de apoyo son parte del EZLN) $)^{6}$. Mantener una franca exterioridad entre las comunidades y lo que, con intenciones despectivas o por lo menos reduccionistas, Estrada llama la "guerrilla" es uno de los objetivos evidentes de dicho planteamiento. Sin embargo, este modelo entraña una visión singularmente pobre de las inte-

\footnotetext{
${ }^{6}$ Estrada, 2007: 387-389. Esta exterioridad viene planteada (de una manera que no deja de ser problemática) desde el título del libro: $\mathrm{La}$ comunidad armada rebelde y el EZLN.
}

racciones sociales, al tratar de reducirlas a una sistemática imposición desde arriba hacia abajo. Pero es dudoso que se pueda mantener apoyo y consentimiento en un sistema puramente impositivo sólo mediante intimidaciones, engaños y castigos, o por mecanismos de cooptación clientelar. Son precisamente otras formas de relación las que sugiere el estudio dedicado a La Garrucha, el cual analiza "un diálogo entre una comunidad agraviada, que contaba ya con un discurso revalorativo de la dignidad del colectivo y en busca de alternativas para transformar sus condiciones, y un grupo clandestino que planteaba la lucha armada como vía de liberación”. También menciona al EZLN como una "estructura políticomilitar plenamente jerarquizada" que, al mismo tiempo, "se conformó y se nutre en buena medida de redes sociales informales desplegadas por quienes constituyen su base social" (pp. 36-38). A partir de estas observaciones, sintomáticamente "olvidadas" en las consideraciones finales, se podría llegar a un análisis más complejo y más dinámico de las interacciones que ha ido construyendo el zapatismo comunitario. Si bien resultaría absurdo sorprenderse de que existan órdenes en una organización políticomilitar o que su dirigencia tenga una clara posición de mando (lo que el EZLN ha reconocido), un análisis serio empezaría en el momento de reconocerles a las comunidades un papel activo en la conformación de sus propias historias como comunidades zapatistas (o parcialmente zapatistas). Sus redes no se desvanecen; sus asam- 
bleas no se desvirtúan bajo la autoridad del "responsable", ni tampoco se someten unilateralmente a la de un alto mando. Se trataría de observar y entender interacciones y negociaciones permanentes (incluso con quienes detentan posiciones de poder), para decidir lo que se puede hacer y lo que no. Son esos procesos complejos, todavía en la sombra, los que han dibujado el caminar de las comunidades zapatistas y la construcción comunitaria, municipal y supramunicipal del proyecto de autonomía con el cual se han identificado las bases de apoyo zapatistas.

Antes de seguir, debo dedicar unos comentarios a la propia contribución de Marco Estrada, pues es evidente que el caso de Buena Vista Pachtán fue elegido para poder evidenciar cierto tipo de relación entre comunidad y proyecto zapatista. Afiliada a la Unión de Ejidos Tierra y Libertad y a la CIOAC a partir de 1982, la comunidad se integra al EZLN en 1993 (o 1994), mientras la mitad de las bases de apoyo dejan esta organización en 1996 para reintegrarse a la CIOAC. El autor toma claramente posición en favor del "realismo" de la CIOAC, cuyos miembros firmaron con el gobierno los Acuerdos Agrarios que les permitieron beneficiarse de la casi totalidad de las tierras tomadas a raíz del levantamiento, mientras las bases zapatistas se quedaron sin nada (pp. 107-108). Que el investigador tenga una opinión personal no representa ningún problema, pero sí lo es en la medida en que lleva a una presentación sesgada de los datos con la intención de desacreditar a una de las partes. La posición de los zapatistas, que se quejan de la traición de los "cioaqueros", no está considerada con seriedad; más bien el dispositivo argumentativo pretende validar la posición de la CIOAC, avalada como expresión de las aspiraciones reales de los campesinos, mientras se afirma que el EZLN, preocupado por establecer una correlación de fuerzas nacional, poco caso hacía de las necesidades materiales de sus bases (p. 116). Es curioso que Estrada reconozca que la vía asumida por la CIOAC no hubiera sido posible sin el levantamiento, de tal forma que no se entiende bien cómo se puede concluir que una opción estrictamente política hubiera resultado "más efectiva" (p. 108). La misma frase opone "dos vías de acceso a la tierra: la armada (EZLN) y la política (CIOAC)", lo que resulta doblemente sesgado, en primer lugar porque los miembros de la CIOAC optaron por negociar después de participar en el levantamiento y las ocupaciones de tierras, y en segundo lugar porque el EZLN, a partir de febrero de 1994, también optó por negociar con el gobierno federal. A esto se añaden dos afirmaciones infundadas: se menciona que el EZLN se negó a participar en los Acuerdos Agrarios porque su política de resistencia se sintetizaba en un "nada con el gobierno" (p. 106) y porque buscaba "una desestabilización política [que] generarían [sic] las condiciones de una crisis mayor del sistema político" (p. 115). Los habi- tantes de Pachtán firmaron los Acuerdos Agrarios en junio de 1996, de tal forma que difícilmente se entiende cómo el autor puede atribuirle al EZLN el lema "nada con el gobierno", el cual corresponde efectivamente a la postura adoptada a partir de 2001, pero resulta un absurdo si se refiere al periodo en el cual el EZLN participaba en las Mesas de San Andrés (en este contexto, la segunda afirmación no pasa de ser una opinión personal muy discutible). Los Diálogos de San Andrés son precisamente el elemento contextual que, de manera intencional, Estrada se cuida de no mencionar. Tomar en cuenta este contexto obligaría, por lo menos, a restituirle su significado a la postura zapatista: no se trataba de rechazar cualquier discusión con el gobierno, sino más bien de llevar a cabo los Diálogos y permitir una salida negociada del conflicto. Los Acuerdos Agrarios correspondían a una estrategia federal, implementada con recursos masivos y una prisa inaudita, para cooptar a los aliados del EZLN y debilitarlo en el contexto de los Diálogos de San Andrés. Descartar estos datos contextuales entraña una franca parcialidad al opacar el sentido de la postura zapatista.

El más atrevido de los saltos generalizantes que incluyen las consideraciones finales bien puede calificarse como trampa argumentativa. Si queda claro que las comunidades de Veracruz, Saltillo, Nuevo Francisco León y aparentemente la de El Coloquil utilizaron el levantamiento, y en cierta 
medida la denominación de "zapatistas", para conseguir sus objetivos agrarios, Marco Estrada no duda en suponer que los "individuos y comunidades que se integraron 'orgánicamente' al EZLN mucho antes de $1994 \mathrm{y}$ permanecieron en él después de esta fecha" lo hicieron adoptando la misma lógica y el mismo "pragmatismo, basado en lo que se puede denominar 'lealtad estratégica”' (p. 432). ¿Cómo equiparar la trayectoria de quienes nunca se integraron al EZLN y la de individuos o comunidades que llevan 15 o 20 años adentro de esta organización?, ¿qué queda de la proclamada diversidad de "los zapatismos", si ni siquiera se tiene el cuidado de analizar de manera diferenciada comunidades zapatistas y no zapatistas?, ¿dónde está el cuidado en el manejo de las generalizaciones que cualquier referencia a un planteamiento "microhistórico" debería implicar? De hecho, ni siquiera el caso de Buena Vista Pachtán podría servir de paradigma para "entender" la dinámica de las comunidades con fuerte implicación en el zapatismo, ya que su adhesión se dio sólo en 1993 o 1994 y quizás ni siquiera implicó una ruptura completa con sus anteriores organizaciones ${ }^{7}$. Si el momento clave del auge del EZLN se dio entre 1988 y 1992, cualquier intento honesto de entender la dinámica de las comunidades zapatistas en su núcleo central tendría que enfocarse

${ }^{7}$ Al leer el testimonio de dirigentes de la Unión de Ejidos Tierra y Libertad (UETL) (Estrada, 2007: 462), uno se pregunta si los habitantes de Pachtán nunca dejaron de pertenecer a esta organización y a la CIOAC, lo que no se menciona en el presente estudio, pero que haría aún más superficial su paso por el zapatismo. en las que se integraron a la organización durante este periodo.

La idea de una acción pragmática orientada por intereses principalmente materiales viene completada por la noción de "equivalentes funcionales", tomada de Niklas Luhmann. La intención de este préstamo es obvia. Consolida la presentación del EZLN (y de otros actores) como "agentes externos" a las comunidades y permite reducir su "propuesta discursiva" a una "cuestión secundaria” para los indígenas, mientras lo único que les importaría sería la fuerza organizativa disponible para la consecución de sus propios objetivos. Mientras este "aparato teórico" se despliega para ocupar los últimos párrafos del libro, las convicciones de los actores del movimiento zapatista quedan arrinconadas en una escueta nota de pie de página (p. 432). En este punto, incluso la referencia "microhistórica” termina cargada de implicaciones discutibles ya que, si bien menciona la necesidad de articular los niveles nacional y local, Estrada afirma que las opciones de los actores deben comprenderse esencialmente a partir de los "intereses y conflictos muy puntuales que sólo se entienden en su lógica de operación y significado en el nivel local", mientras las intervenciones foráneas sirven de "lenguajes" que los actores se apropian para "configura[r]", en términos pragmáticos, "identidades políticas plásticas”, instrumentalizadas en el marco de los conflictos y las situaciones locales. Además de encerrar el sentido de la acción so-

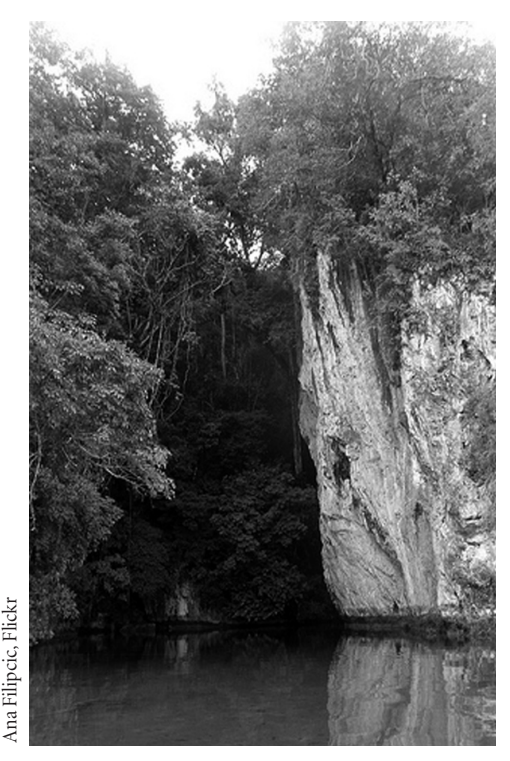

Laguna Miramar, 2010.

cial en un marco francamente local, lo que así se excluye, mediante un "golpe de Estado" teórico, es la posibilidad de una apropiación más profunda de las propuestas impulsadas por actores no indígenas; es la posibilidad de un "encuentro", una convergencia o una adecuación (aunque sea parcial) entre ambas partes $^{8}$. Más aún, ni siquiera contempla la posibilidad de que los discursos y los actores "foráneos" puedan transformarse a lo largo de su interacción con la realidad local (por razones relacionadas con esta interacción o con evoluciones más

\footnotetext{
${ }^{8}$ Incluso la "Palabra de Dios" figura entre estos "discursos foráneos", a pesar de que decenas de miles de indígenas asumieron la pastoral impulsada por la Diócesis como parte de su forma de vivir y ver el mundo, de tal suerte que parece muy atrevido suponer que se trate de una simple "propuesta discursiva", utilizada pragmáticamente.
} 
generales). Sin embargo, en el esquema paradójicamente un tanto esencialista que prevalece aquí, los actores y las propuestas externos siempre son lo que son, mientras los indígenas y las comunidades también son lo que son (con sus inmutables anhelos, que el investigador está seguro de haber encajonado en sus categorías). Por eso, se puede descartar a priori que los dirigentes mestizos y el proyecto del EZLN hayan sufrido transformaciones profundas a lo largo de 25 años de apropiaciones y experiencias vividas en el mundo indígena de Chiapas. Si bien empobrece el análisis, la incapacidad para considerar formas complejas de interacciones es indispensable para mantener el dogma de una profunda exterioridad entre el EZLN y las comunidades indígenas.

No deja de ser problemática la convicción con la cual el investigador pretende conocer, y definir con sus propios términos, las motivaciones de los actores, sin dedicarle mucha atención a lo que ellos opinan al respecto. Estrada expresa con toda seguridad lo que buscan los indígenas chiapanecos: "salir del circuito de exclusión social”, conseguir el "mejoramiento de sus condiciones de vida" y lograr su "integración al resto de la sociedad nacional" (p. 433). En el estudio relativo a Pachtán, y en su libro anterior, resalta el segundo de estos criterios y en especial la lucha por conseguir tierras. En esta visión reduccionista de la intencionalidad de los actores se esconden tres opciones que hablan más que nada de quien las formula.

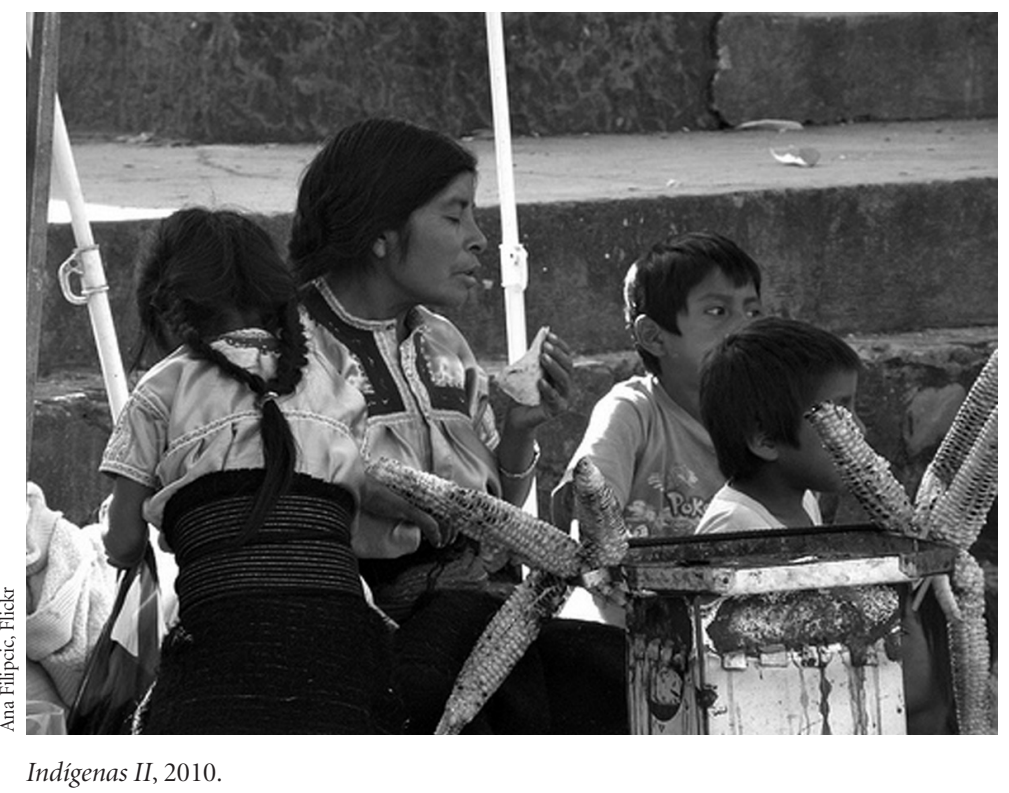

Una podría definirse como desarrollista y se apura, en sintonía con los discursos neoliberales, en proclamar la muerte del campo mexicano. La segunda implica una mirada despectiva hacia los grupos sociales subalternos, cuyo actuar, basado en conocimientos limitados, viene guiado por intereses y necesidades esencialmente materiales, mientras los grupos dominantes, al contar con plena capacidad de razonamiento, son capaces de elaborar proyectos políticos y sociales articulados. En fin, implica un esquema integracionista que presupone un deseo universal de adaptarse (en "una posición de igualdad") a la realidad nacional, haciendo caso omiso de la posibilidad de que los sujetos sociales puedan anhelar no una posición en la sociedad nacional tal como existe sino una transformación de esa realidad, y puedan por lo tanto dedicar sus esfuerzos a la construcción de otro tipo de organización social ${ }^{9}$.

Quizás este marco conceptual busque corregir las afirmaciones del estudio anterior de Marco Estrada, en el cual prevalecía la temática de la manipulación y el engaño de los indígenas por la dirigencia zapatista, con el inconveniente de perpetuar una visión infantilizante de los indígenas, incapaces de actuar de manera razonada y voluntaria. Ahora, se les concede un estatus de actores en pleno sentido, a tal grado que son ellos quienes "manipulan" las propuestas "foráneas" en aras de conseguir sus propios objetivos. Más bien

\footnotetext{
${ }^{9}$ Lo dicen varios de los testimonios ofrecidos por este libro, muy selectivamente leídos en las consideraciones finales. Son muchos los zapatistas que explican que su lucha no es principalmente por la tierra o por recursos materiales (si bien ésta es una dimensión importante), mientras el testimonio de Juan (Huitiupán) indica una clara capacidad para situar las implicaciones de la lucha en una perspectiva nacional (p. 309).
} 
dicho, las dos propuestas se combinan: la "guerrilla" usa a los indígenas para sus fines políticos nacionales, mientras los indígenas usan a ésta para conseguir sus objetivos esencialmente locales y materiales. Esta relación de instrumentalización recíproca pretende comprobar el postulado inicial según el cual los objetivos del EZLN son ajenos a las necesidades reales de los indígenas (argumentación que sólo podría funcionar si se aceptara que estas necesidades quedan mejor definidas por el científico social que por los actores mismos). En todo caso, estos planteamientos demuestran una rígida adecuación a los marcos interpretativos utilitaristas, efectivamente dominantes en las ciencias sociales, pero no por eso menos cuestionables. ¿Estamos realmente obligados a encerrarnos en una concepción instrumental de la acción social, orientada por el cálculo racional beneficios/costos y pensada en términos de interés?, ¿no deberíamos analizar esta concepción no como una opción natural sino como una construcción histórica relacionada con los fundamentos de la modernidad y del sistema capitalista? Algunas propuestas sociológicas sugieren que si bien el marco utilitarista permite analizar una parte del mundo social, yerra necesariamente a la hora de pretender dar cuenta de la totalidad del mismo ${ }^{10}$.

Los límites del marco interpretativo utilitarista quedan evidenciados claramente en este libro. El esquema

\footnotetext{
${ }^{10}$ Véase Caillé, 2009 y 1993.
}

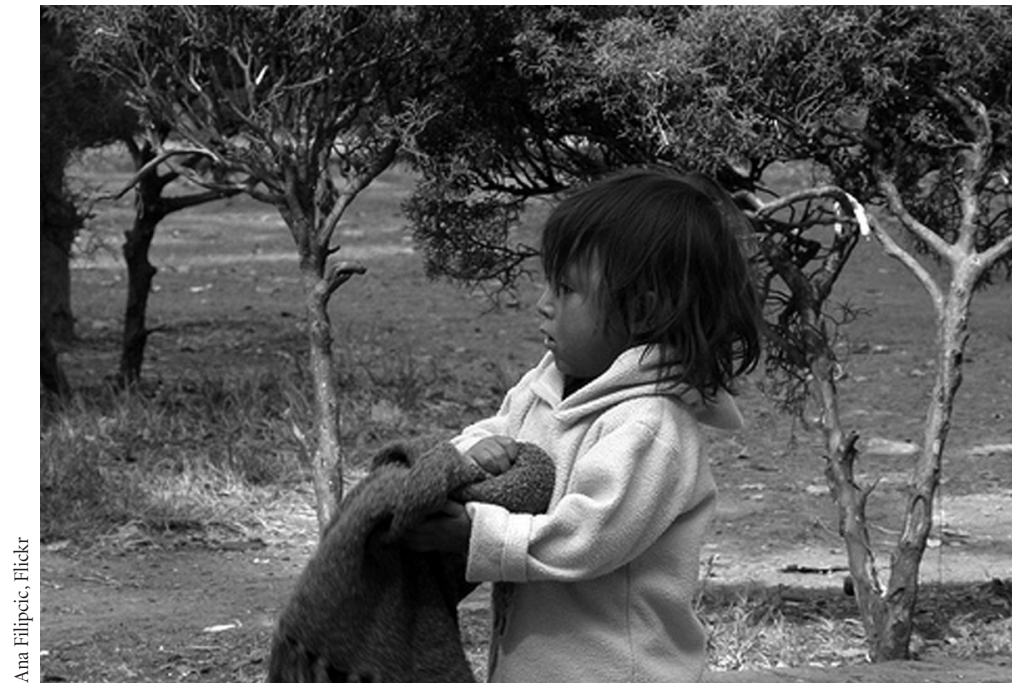

Niña, 2010.

que pretende separar, por un lado, una guerrilla con una propuesta discursiva revolucionaria-socialista y, por el otro, unos indígenas en busca de mejorías materiales e integración a la sociedad nacional, resulta inoperante para dar cuenta de lo que significa el zapatismo en las comunidades indígenas de Chiapas. Al mismo tiempo, la omnipresencia de este marco utilitarista permite entender por qué en este libro se ve y se escucha poco al zapatismo, de tal suerte que un indígena afiliado al EZLN difícilmente se reconocería en él. Se oye tímidamente esa voz en algunas páginas, pero se descarta en el panorama final que del zapatismo se ofrece. Lo que tenemos aquí es un libro que pretende releer el zapatismo desde las comunidades indígenas de Chiapas, pero que no permite entender cuál es el sentido de esta lucha para quienes se identifican con ella.
Para abordar este continente ignorado hubiera sido necesario hacerle caso a algunas palabras como "dignidad" (y a todo lo que ejemplifica) o"autonomía" (y a los esfuerzos cotidianos que implica su construcción). Habría sido necesario escuchar las voces de los zapatistas de La Garrucha que, en este mismo libro, sugieren lo importante que es haber construido instancias de autogobierno y un sistema educativo vividos como propios (como manera de liberarse de la dependencia respecto de un Estado percibido como ajeno o adverso (p. 51). Habría sido necesario tratar de entender cómo el levantamiento zapatista y la construcción de la autonomía contribuyen para sus actores a dar un nuevo sentido a sus vidas, y cuáles son las implicaciones de ese sentimiento de que por fin valemos para quienes llevan en la sangre siglos de desprecio y opresión. Habría 
sido necesario admitir que decenas de miles de indígenas pueden ser movidos por un proyecto de transformación social, por el anhelo de construir una organización colectiva inédita que no repita ni sus "usos y costumbres" ni los esquemas revolucionarios de corte modernista-estatista. Habría sido necesario preguntarse seriamente qué sentido puede tener que la rebelión zapatista haya sido reconocida como referente por muchos movimientos sociales, en especial en América Latina, y haya sido objeto de reflexión por parte de académicos no menos respetables y dignos de ser citados que otros (para dar un solo ejemplo, Immanuel Wallerstein, muchos años presidente de la Asociación Internacional de Sociología, ha caracterizado a la rebelión zapatista como "el movimiento social más importante" en la actualidad) ${ }^{11}$.

\section{Quisiera ahora ampliar la reflexión y} proponer unas observaciones relativas a la cuestión del punto de vista en las ciencias sociales. Juan Pedro Viqueira advierte que el libro no pretende "ni una imposible objetividad científica", "ni una absurda imparcialidad"(p. 17). La aclaración es particularmente bienvenida, pues estas dos palabras, y en especial la de "imparcialidad", son con las que Marco Estrada ampara su texto La comunidad armada rebelde ${ }^{12}$. La introducción de este libro alaba a la ciencia que, gracias a su rigor, alcanza-

\footnotetext{
${ }^{11}$ Wallerstein, 2008: 220.
}

ría un conocimiento certero e imparcial. Se establece así una línea divisoria entre el científico social, que se ubica en el terreno de la verdad, y los demás mortales (en especial quienes son objeto de su investigación), que viven en el universo del mito. Sin embargo, esta proclama de cuño positivista no pasa de ser la máscara de innumerables infracciones a sus propias reglas y de la parcialidad que anima el autor en su relación con el zapatismo ${ }^{13}$.

$\mathrm{Al}$ contrario de lo que pretende el credo positivista, no hay conocimiento "puro" del objeto en sí mismo. El investigador tiene una participación activa en la producción de la investigación y los conocimientos no son independientes del proceso que los ha producido. Es por lo tanto indispensable tomar en cuenta la intervención del investigador en la producción del conocimiento y la posición desde la cual lo produce. Más bien, siendo la producción cien-

${ }^{12}$ Estrada, 2007: 48-50.

${ }^{13}$ Sería otra tarea identificar con toda precisión lo que permite poner en duda los análisis de $L a$ comunidad armada rebelde: uso de testimonios de exzapatistas tomados como verdad absoluta, sin contextualización ni indicaciones sobre la trayectoria y la posición desde la cual hablan los informantes, es decir, sin aludir mínimamente a la necesaria crítica de cualquier fuente utilizada (algo que, al contrario, Sonia Toledo toma justamente en cuenta, dando credibilidad a su intento por reconstituir lo ocurrido en Santa Catalina Huituipán); afirmaciones que no se sustentan en datos precisos ni fuentes (por ejemplo, pp. 474, 487, 596-597); lectura forzada de los testimonios o de los datos presentados, siempre en el sentido de la imparcial opinión del autor (por ejemplo, pp. 385, 480-482, 500-501, 511512); conocimiento superficial de la autonomía zapatista, tanto en lo que se refiere a los municipios como a las Juntas de Buen Gobierno (pp. 536-537, 550-562). tífica un proceso mucho más colectivo de lo que parece, habría que tomar en consideración el campo académico en su conjunto (en la medida en que predispone y valida los trabajos individuales) como uno de los factores determinantes en el proceso de producción del conocimiento.

La participación activa del investigador en la producción del conocimiento — su posición específica en el campo científico y en el campo social- podría caracterizarse distinguiendo varios niveles. En uno de ellos podríamos ubicar el marco teórico, conceptual y metodológico al cual recurre la investigación, es decir lo que Marc Bloch llamaba el "cuestionario", conjunto de preguntas, hipótesis, nociones (y también prejuicios) que orientan la investigación, la construcción del objeto y de los datos recabados, así como su interpretación (es preciso observar que un cuestionario no es una simple ocurrencia individual, sino que integra la construcción colectiva de una disciplina, pues implica tomar en cuenta sus avances, sus límites y sus posibilidades de renovación). En esto, la intervención activa del investigador es indispensable, pero una condición de la cientificidad de su trabajo es la capacidad de autorreflexión sobre su propio cuestionario, sobre las implicaciones y limitaciones de su marco conceptual y metodológico.

En un nivel más general, podríamos ubicar el mundo histórico-social, entendido en todas sus dimensiones materiales y mentales, 
que determinan o interfieren en la producción de conocimientos científicos. Es preciso referirnos aquí al trabajo de "objetivación participante", entendido como el esfuerzo de quien pretende conocer por conocerse a sí mismo, por identificar de qué manera su propia posición en el campo social, como en el campo académico, afecta los conocimientos que trata de producir ${ }^{14}$. No hay ciencia sin reflexividad, ni hay ciencia social sin una sociología de los científicos sociales. Si la sociología es una “cazadora de mitos", según la expresión de Norbert Elias que retoma Marco Estrada, también tiene que perseguir los mitos de los sociólogos y los demás científicos sociales.

En fin, hay que considerar la posición asumida en el campo social.

Podría reducirse a las posiciones políticas, religiosas o filosóficas explícitas, por ejemplo, de simpatía u hostilidad respecto del zapatismo. La cuestión sin embargo es más profunda y llevaría a oponer la constitución de conocimientos sobre los movimientos sociales y la construcción de saberes desde y con los movimientos sociales. Una de las apuestas de la segunda opción consiste en romper la asimetría entre sujeto y objeto del conocimiento (buscando aprender del potencial cognitivo de los actores sociales, imaginando formas de coproducción de saberes, al mismo tiempo que practicando la objetivación participante). Para limitarme a estimaciones directamente relacionadas

\footnotetext{
${ }^{14}$ Bourdieu, 2003a y 2003b.
}

con la presente reseña, consideraré los efectos de las posturas explícitas respecto del zapatismo. Evidentemente, una investigación que no hiciera más que confortar posturas políticas previas ofrecería resultados muy pobres. Tampoco puede justificarse un manejo selectivo de la información o un rigor argumentativo de geometría variable según convenga o no a la postura política del investigador. Si bien la imparcialidad es inaccesible, hay formas de parcialidad que son claramente inaceptables. Identificarlas basta (o debería bastar) para desacreditar la investigación. En el caso que nos ocupa, un primer paso consistiría en que quienes tienen simpatías por el zapatismo, no por eso se mantengan ciegos a sus errores y acepten cuestionar visiones idealizadas o simplificadas. Recíprocamente, quienes asumen convicciones adversas y distantes respecto del zapatismo, no por eso tendrían que conformarse con un esquema caricaturizado que descarte sus logros, ni ser sordos al sentido que tiene esta lucha para los indígenas de Chiapas y para muchos otros movimientos sociales. A este respecto, se le podría hacer la siguiente pregunta a Marco Estrada: ¿alguna vez, durante su investigación, se ha dejado sorprender positivamente por lo que ha observado en comunidades zapatistas? Si es que no, ¿̇se deberá a la rigidez de sus esquemas previos? Si es que sí, ¿por qué su trabajo no se abre a una interrogación sobre las implicaciones y las raíces de esta parte para él sorprendente?
En principio, una postura crítica hacia el objeto estudiado podría considerarse más adecuada y fecunda para producir conocimientos válidos, pues inclina a movilizar más intensamente el espíritu crítico y la perspicacia. Por eso, se podría argumentar que una historia - $\mathrm{O}$ una ciencia social— "a contrapelo", mirando al cortejo de los vencedores desde abajo, según la recomendación de Walter Benjamin, y por lo tanto teniendo más inquietud por identificar y entender las formas de dominación social, podría (bajo ciertas condiciones) alcanzar más agudeza analítica que una ciencia social que se conforma con el marco social imperante y, por lo tanto, minimiza los efectos de la opresión y la injusticia. Siguiendo la misma lógica (y siendo evidente que el criterio mencionado no es el único en determinar la calidad de una investigación), se podría pensar que es una condición más favorable analizar este movimiento desde una postura hostil que desde simpatías hacia él. Sin embargo, el antizapatismo militante puede resultar un factor tan desfavorable como una pasión filozapatista acrítica, si es que la investigación se deja orientar por el deseo de comprobar fracasos y errores, mientras se ocultan o se aminoran logros y alcances. Y si evita estos errores evidentes, no por eso supera el riesgo de mirar desde afuera, si no es que desde arriba.

Quizás una de las mayores dificultades de las ciencias sociales sea combinar el distanciamiento de la mirada crítica con una comprehen- 
sión íntima, desde adentro, de los fenómenos estudiados (según la familiaridad o exterioridad con lo que estudia, la dificultad puede ubicarse de un lado o del otro de este eje). La comprehensión desde adentro implica escuchar a los sujetos, capacidad para desprenderse de sí mismo y un paciente esfuerzo para entender a profundidad las categorías "endógenas" (las de los sujetos sociales), mientras la distancia crítica hace legítimo recurrir a categorías y conceptos "exógenos" (que amplían la capacidad analítica, siempre y cuando no pretendan sustituir la reconstitución de la lógica propia de las representaciones "endógenas”). Cualquier investigación que no logre combinar comprehensión desde adentro y distanciamiento crítico, no puede pretender dar cuenta cabal de su objeto. Es de temer que el marco teórico dominante del presente libro impida alcanzar la primera condición.

En fin, una última consideración: el zapatismo se niega a la mirada unilateralmente objetivante. Por esta razón, y por algunas otras, habría que reconocer todo lo que no se alcanza a ver del zapatismo. Habría que admitir que los investigadores sociales (en especial los que asumen sin distanciamiento esta mirada unilateralmente objetivante) no están en condición de adentrarse en lo que el zapatismo es y significa para quienes se identifican con su lucha. Por muy molesto y difícil de aceptar que pueda resultar, sería un sano ejercicio de prudencia y de modestia que los estudiosos del zapatismo asuman y hagan constar los límites de su mirada, en el contexto de una guerra que no ha terminado.

\section{Bibliografía}

Baronnet, Bruno, 2009, Autonomía y educación indigena. Las escuelas zapatistas en Las Cañadas de la Selva Lacandona (Chiapas), tesis de doctorado en Ciencia Social con especialidad en Sociología, El Colegio de MéxicoUniversité de Paris-III, México.
Bourdieu, Pierre, 2003a, "L'objectivation participante", Actes de la recherche en Sciences Sociales, núm. 150, pp. 43-57.

— 2003 b, El oficio de científico. Ciencia de la ciencia y reflexividad, Anagrama, Barcelona.

Caillé, Alain, 2009, Théorie anti-utilitariste de l'action. Fragments d'une sociologie générale, La Découverte, París.

__, 1993, La démission des clercs. Les sciences sociales et l'oubli du politique, La Découverte, París.

Estrada Saavedra, Marco, 2007, La comunidad armada rebelde y el EZLN. Un estudio histórico y sociológico sobre las bases de apoyo zapatistas en Las Cañadas tojolabales de la Selva Lacandona (1930-2003), El Colegio de México, México.

Mora, Mariana, 2008, Decolonizing Politics: Zapatista Indigenous Autonomy in an Era of Neoliberal Governance and Low Intensity Warfare, tesis de doctorado en Filosofía, Universidad de Austin, Texas.

Wallerstein, Immanuel, 2008, Historia y dilemas de los movimientos antisistémicos, Contrahistorias, México. 